\title{
Reproductive Biology of T. chinensis and T. ramosissima (Tamaricaceae: Theineae) from Gansu, Northwestern China
}

\author{
Min Chen ${ }^{1}$, Xue-yong Zhao ${ }^{1}$, Xiao-an Zuo ${ }^{1}$, Ya-yong Luo ${ }^{1}$, Jie Lian ${ }^{1} \&$ Yang-chun Zhu ${ }^{1,2}$ \\ ${ }^{1}$ Cold and Arid Regions Environmental and Engineering Research Institute, Chinese Academy of Sciences, \\ Lanzhou, China \\ ${ }^{2}$ University of Chinese Academy of Sciences, Beijing, China \\ Correspondence: Min Chen, Cold and Arid Regions Environmental and Engineering Research Institute, Chinese \\ Academy of Sciences, Lanzhou, China. Tel: 86-1-510-125-1818. E-mail: chenmin1360@126.com
}

Received: August 9, 2015 Accepted: September 5, 2015 Online Published: October 15, 2015

doi:10.5539/jas.v7n11p156 URL: http://dx.doi.org/10.5539/jas.v7n11p156

\begin{abstract}
Tamarix. chinensis and Tamarix. ramosissima are ecologically important species in the arid region of Northwest China, and have been widely studied in recent years. The reproductive biology of $T$. chinensis and $T$. ramosissima was studied to determine the main pollination system and pollen limitation of these species, providing the first experimental data on reproductive success in the Tamaricaceae. This study was conducted, including observations on phenology and floral trait of flowers, insect visits and pollinator behavior. Experimental pollination treatments were performed to assess self-compatibility, outcrossing and self-pollination. Pollen limitation and reproductive success were assessed by fruit- and seed-set. The blooming duration and flowering peak were different between $T$. chinensis and $T$. ramosissima, being longer in the former. Both species were pollen-limited, and pollen limitation was more intense in T. ramosissima than that in T. chinensis. In $T$. chinensis, Megachile (Amegachile) kagiana was found to be the most frequent and effective pollinator, Apis mellifera was the frequent visitor in T. ramosissima. We suggested that pollinator behavior is closely associated with floral phenology. Some important differences were found from the study on two species in floral phenology and the primary pollinator behavior. Outcrossing was dominant and that self-pollination played a complementary role to assure production. Both species display a highly adaptive breeding system, and it's also the evolution of reproductive biology.
\end{abstract}

Keywords: reproductive, pollination, pollen limitation, pollinator, breeding system

\section{Introduction}

Reproductive success in variable environments in which pollination may be uncertain is a common problem that confronts many plants (Ai et al., 2013). Pollination is a key process as the first stage in sexual reproduction of plants, and an essential prerequisite for the development of fruits and seeds (Kevan et al., 1990). Therefore, pollination affects a variety of ecological and evolutionary processes of many plant species, such as floral attraction, plant mating system and population persistence (Bond, 1994; Kearns et al., 1998; Ashman et al., 2004; Ashman \& Morgan, 2004). During the short growing seasons, harsh weather and low densities of pollinators could affect the effective pollination (Ai et al., 2013; Ashman et al., 2004). Studying reproductive biology is helpful to understanding of pollination success, as well as natural factors influencing dynamics of populations (Arias-Cóyotl et al., 2006).

The flowering plants under natural pollination conditions often suffer from pollen limitation (Ashman et al., 2004; Knight et al., 2006). Pollen limitation occurs when plant reproduction is limited by the quantity or quality of pollen received (Byers, 1995; Aizen \& Harder, 2007). When pollen limitation is observed in fragmented habitat, it is often interpreted as evidence for pollinator limitation of reproduction (Stuart \& Stephanie, 2010). Sexual selection theory once optimistically predicted that plant reproduction should not be limited by pollen receipt (Janzen, 1977). In contrast, recent reviews indicated that pollen limitation is widespread in plants (Burd, 1994; Larson \& Barrett, 2000; Knight et al., 2006). The potential consequences of pollen limitation on plant reproduction have been extensively studied over the last several decades (Burd, 1994; Larson \& Barrett, 2000; Knight et al., 2006; García-Camacho \& Totland, 2009). To examine the consequences of pollen limitation at population level, most studies evaluate the effect of pollen addition in the context of the entire plant life cycle 
(Ashman et al., 2004). It seems logical to expect that pollen limitation will have negative consequences for the fruit set or seed production of the life cycle (Ashman et al., 2004). The arid plants depend on pollinator services are most likely to be pollen limited because insect pollinators are lower in diversity and abundance in these habitats. In this paper, we discuss the limitations of this approach, and argue that we should diversify our methods in order to improve our understanding of the dynamic interaction between pollen deposition and resource allocation.

The genus Tamarix has a Mediterranean origin (Baum, 1978). T. chinensis Lour and T. ramosissima are ecologically important plants and widely distributed in arid regions. They play an important role in the establishment of dryland vegetation because their root system are very efficient in absorbing water and make plants drought and salt resistant (Li et al., 1990). In addition, they (as the important key species) have important effect on sand fixation and vegetation productivity. Their flowers and leaves can be used as medicine (Li et al., 1990). Understanding the mechanisms of flowers and fruits production is particularly important for both species, since their flowers and fruits are important economic income resource for local people.

Previous studies on Tamarix have focused mostly on geographical distribution, biological characteristics, physiological stress and molecular biology (Glenn \& Nagler, 2005; Milbrath \& DeLoach, 2006; Whiteman, 2006; Hudgeons et al., 2007; Morman et al., 2009). Based on the understanding of the above research and practical concern, as well as the scarcity of studies on reproductive biology and pollen limitation data of $T$. chinensis and T. ramosissima, we served to improve their reproductive efficiency. The main goal of this study is testing the reproductive biology of $T$. chinensis and T. ramosissima. In this sense, we compared the pollination biology and pollen limitation of the both species through testing the difference influence on fruit and seed set. We hypothesised that: 1) pollen limitation will be different in the both species, and may be a relationship across populations between pollinator visitation frequency and Pollen Limitation index; 2) different pollinator types may influence differences in reproductive patterns, pollinators and their activity may affect seed set of both species. In addition, we also test the co-effect of outcrossing and self-pollination in the evolution of breeding system.

\section{Materials and Methods}

\subsection{Species}

Both species are shrubs and endemic to China where they are distributed in Northwest Gansu, North Shangdong and Southeast Hebei. The genus Tamarix has 18 species and a variant, includes five new species (Li et al., 1990).

T. chinensis has a well-developed root system and grows up to 5-6 $\mathrm{m}$. Pink or purple bisexual flowers are organized in inflorescence with five stamens. T. ramosissima is usually 2-3 $\mathrm{m}$ in height and the root system can reach groundwater at a depth of $10 \mathrm{~m}$, and it has pink bisexual flowers with five petals and five stamens (Li et al., 1990).

\subsection{Study Area}

The studied area is in Linze Inland River Basin Comprehensive Research Station (Figure 1). It is located on the Gansu province of Northwest China at the Southern edge of Badain Jaran Desert (between $37^{\circ} 50^{\prime}-42^{\circ} 40^{\prime} \mathrm{N}$ and $\left.100^{\circ} 02^{\prime}-100^{\circ} 21^{\prime} \mathrm{E}\right)$. Annual rainfall is about $117 \mathrm{~mm}$, and the mean annual pan evaporation is $2390 \mathrm{~mm}$. Annual average temperature is $7.2{ }^{\circ} \mathrm{C}$, while the maximum is $39^{\circ} \mathrm{C}$ and the minimum is $-27^{\circ} \mathrm{C}$. 

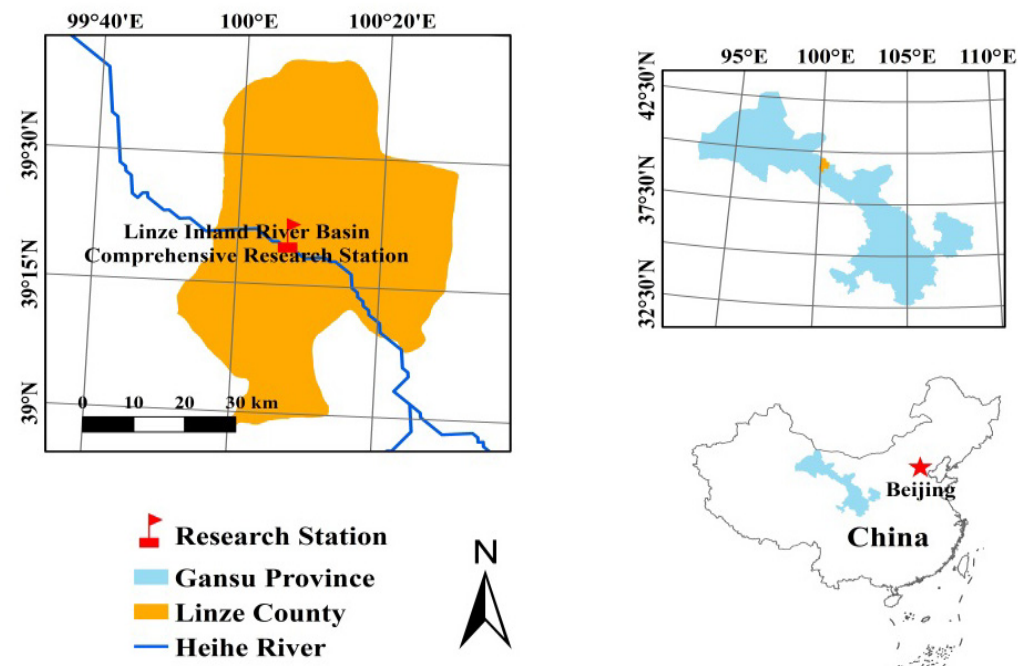

Figure 1. The location of the study area in Gansu Province region, China

For this study, we selected T. ramosissima population in the area, where there were some general and tall plants, such as forests (e.g. Ulmus pumila, Salix matsudana), shrubs (e.g. Caragana microphylla). Flowering time of $T$. ramosissima and these species of plants do not overlap. Average density of T. ramosissima in this area is 12 individuals per $100 \mathrm{~m}^{2}$ and three plots were separated by $200-500 \mathrm{~m}$. The T. chinensis population studied zone is close to an urban area, separated by nearly $5 \mathrm{~km}$ from the $T$. ramosissima zone. This is to distance can avoid the mutual interference of different pollinators in different populations. The surface is covered with the native plants, such as grasses (e.g. Setaria viridis, Phragmites australis, Digitaria ciliaris), forbs (Artemisia scoparia). The average density in this area is 19 individuals per $100 \mathrm{~m}^{2}$ and three plots were separated by $100-300 \mathrm{~m}$ from each other.

\subsection{Phenological Observation}

A total of 20 plants, 10 from T. ramosissima and 10 from T. chinensis were selected to study plant phenology. For each individual plant, the reproductive structures produced (flower buds, flowers in anthesis, and mature fruits) on each branches were counted every 7 days throughout the entire reproductive season (April 2010 to October 2013). We calculated the total number of buds, flowers in anthesis, and mature fruits, as a proportion of the total number of reproductive structures found on each individual plant.

\subsection{Floral Trait}

The bushes under study were visited monthly from April 2010 to October 2013 and the changes in floral trait, such as the flowering period, anther dehiscence, and nectar production were recorded (Spira et al., 1992; Kudo, 1993). Measurements included the lengths of the corolla, petals and stamens. The timing of following events was recorded: initiation of anthesis, opening of the flowers, pollen release, flower number started to close and completely closed. These observations were further supported by continuous filming of anthesis. In addition, samples, flowers and their visitors were also filmed with video cameras for $160 \mathrm{~h}$.

\subsection{Pollen Limitation}

Ashman et al. (2004) examined the effects of pollen limitation at the whole-plant level but did not include the potentially confused effects of resource reallocation. In this study, we used two complementary controls, one from manipulated plants and the other from non-manipulated ones as procedural control. Then three treatments were set up to estimate the relative impact of wind and insect pollination on fruit set: (1) Control (C treatment), flowers from manipulated plants; (2) Procedural control (CC treatment), flowers from non-manipulated ones, $\mathrm{CC}$ flowers were used to detect possible effects of pollen supplementation to resource allocation (Wesselingh, 2007); and (3) Pollen added (PA treatment), the PA treatment was carried out when the flowers opened and the plants were hand-pollinated by saturating the stigma with fresh pollen obtained from another plant which was at least $10 \mathrm{~m}$ away. The newly receptive flowers were pollinated from 7:00-19:00 and lasted for seven days.

To evaluate pollen limitation, a pollen-supplementation experiment was conducted in six plots. A total 576 tagged flowers (six plots, twelve plants per plot, one inflorescence per plant, eight flowers in each inflorescence) 
were collected.

In each plot, we randomly labelled twelve healthy plants that were at the same flowering stage. One inflorescence was sampled from all targeted plants with similar size. There were eight plants received fresh pollen. In each received individual, the central part of eight flowers of the inflorescence were labelled, adding fresh pollen in the upper four flowers as the PA treatment and leaving the lower four flowers as the $\mathrm{C}$ treatment. In the four remaining plants, four flowers of each plant were also labelled and regarded as the CC treatment. All the flowers were freely exposed to insect pollinators after they had been opened manually.

In each plot, PA and C flowers were chosen from the same part of the stalks to avoid the effects of flower position on reproduction and pollen limitation (Casper \& Niesenbaum, 1993; Wesselingh, 2007, Gómez et al., 2010). We chose $C$ flowers to be located under PA flowers along the flowering stalk because by doing this, we decreased the potential for resource redistribution, since flowering and fruiting in T. chinensis and T. ramosissima occurred from the bottom up. The $\mathrm{CC}$ flowers in non-manipulated plants were used to detect possible effects of pollen supplementation on re-allocation of resources from $\mathrm{C}$ flowers in manipulated plants (Wesselingh, 2007; Gómez et al., 2010). By the end of the reproductive season, we counted the number of experimental flowers that had produced fruits.

To estimate pollen limitation, the proportion of flowers setting fruit (PL index) was calculated according to the following equation (Larson \& Barrett, 2000):

$$
\mathrm{PL}_{\mathrm{C}} \text { index }=1-\left(\mathrm{RS}_{\mathrm{C}} / \mathrm{RS}_{\mathrm{PA}}\right)
$$

Where, $\mathrm{RS}_{\mathrm{C}}$ is the fruit set of $\mathrm{C}$ treatment and $\mathrm{RS}_{\mathrm{PA}}$ is the fruit set of PA treatment . The PL index ranges from 0 to 1 , and zero means no pollen limitation and 1the highest pollen limitation (Larson \& Barrett, 2000).

\subsection{Observations of Flower Visitors}

During the monthly field visits, pollination was observed and recorded, and pollinators were captured using insect nets for later identification. Each observation period was of six days from 07:00 to 19:00 each day under different weather conditions. Visitors were tracked visually for as long as possible until they left the focal population, and their foraging sequence within and between plants was recorded during each observation period. A pollinator foraging in a flower was considered as a visit. For every visitor observed, the time and visiting behavior as well as its role in pollination of $T$. chinensis and T. ramosissima were also recorded. Pollen preparations were made by a cube of fuchsin-stained jelly over each insect body (Beattie, 1971). Visitation frequency of different visitors to flowers and foraging time were observed and recorded every hour. The visitor visitation frequency $\left(\mathrm{V}_{\mathrm{f}}\right)$ was calculated according to the following equation (Cosacov et al., 2008):

$$
\mathrm{V}_{\mathrm{f}}=\mathrm{V} /(\mathrm{F} \times \mathrm{T})
$$

Where, $\mathrm{V}$ is the total number of visits to flowers, $\mathrm{F}$ is the total number of flowers in the plot, and $\mathrm{T}$ is the observation time in hours (Cosacov et al., 2008).

\subsection{Breeding System}

To investigate breeding system of both species, we used controlled hand pollination on flowers bagged in the pre-anthesis. The ideal sample designed for each treatment was 60 flowers, however due to limitations in the field (e.g. loss of treated flowers by rain or herbivores). Some treatments had different sample sizes. Experiment was conducted in early April. Except the control for testing efficiency, the emasculated and netting, and emasculated without bags, the rest was treated by covering sampled flowers with exclusion bags. The bags were made of a thick waterproof paper and they served to prevent pollination by insects and airborne pollen. The following treatments were conducted: (1) Control, inflorescence with floral buds marked at random and maintained under natural condition, i.e. flowers free to visitors (Dafni, 1992); (2) Non-manipulated self-pollination, flowers covered with exclusion bags were maintained in this condition until fruits matured; (3) Manual cross-pollination, pollen from 10 individual plants collected and used to pollinate flowers of other individual plants whose stamens were previously removed; (4) Emasculated and netting group, emasculation performed before flowers opening and nylon nets with $1 \mathrm{~mm}^{2}$ mesh size were used to prevent insects from visiting flowers which stamens had been previously removed; and (5) Emasculated without bags. In October, all fruits were gathered from the bagging experiment for subsequent germination tests in the laboratory.

The self-compatibility index (SCI) was also calculated (Zapata \& Arroyo, 1978); SCI is the average fruit set after manual self-pollination divided by that of manual cross-pollination. SCI value $\leq 0.2$ indicates self-incompatibility, whereas value $>0.2$ indicates self-compatibility (Zapata \& Arroyo, 1978). 


\subsection{Statistical Analysis}

Data were transformed, using the arcsine square-root function for the whole sample of 20 plants to compare production of reproductive structures (buds, flowers, and mature fruits) between both populations. To determine whether habitat condition affected flower buds, flowers and fruit production, we used generalized linear models for Repeated Measures ANOVA, with plant as the repeat factor in the model. The model used population condition, date and the interaction between date and population condition as categorical independent variables. The dependent variable for each of the three analyses, respectively, was flower buds, flowers or fruit production. Because flower and fruit production do not follow a normal distribution, we used a Poisson distribution for these two analyses. These models use a logarithmic link function.

The quantitative floral characters were compared using one-way ANOVA. The Chi-square test was used to compare fruit set between these treatments. All analyses were performed using the statistical software package SPSS 18.0 for Windows (SPSS Inc. Chicago, IL, USA).

\section{Results}

\subsection{Phenological Traits}

The reproductive season of T. chinensis and T. ramosissima start from April and finished in October. Flower buds were produced throughout the reproductive season but were particularly abundant during mid-June (Figure 2A).

Significant differences were identified in the end of May $(\mathrm{df}=13, \mathrm{~F}=262.7, \mathrm{P}<0.05)$, when markedly more buds recorded in T. chinensis (Figure 2A). In both species studied, most flowers reaching anthesis were observed in the end of June and the last flower by the end of September. Flower production and the flowering peak were different between $T$. chinensis and T. ramosissima, with the former having a longer flowering period (Figure 2B).

Fruits were available from the end of July to October, the production of T. ramosissima peaked at mid-September, while T. chinensis peaked during the last week of August. The pattern of fruits production was significantly different between $T$. chinensis and T. ramosissima ( $\mathrm{df}=8, \mathrm{~F}=116.2, \mathrm{P}<0.05)$ (Figure 2C).
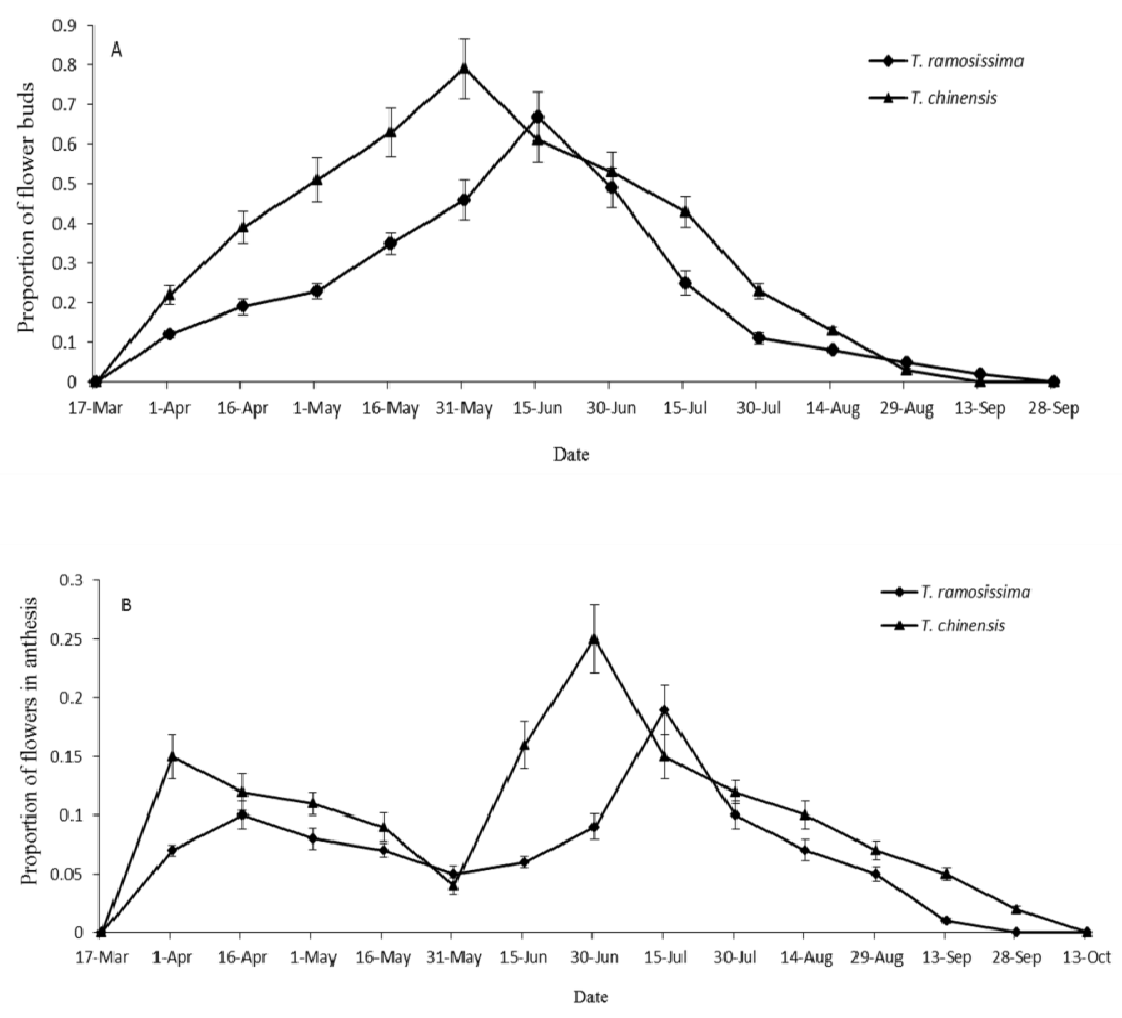


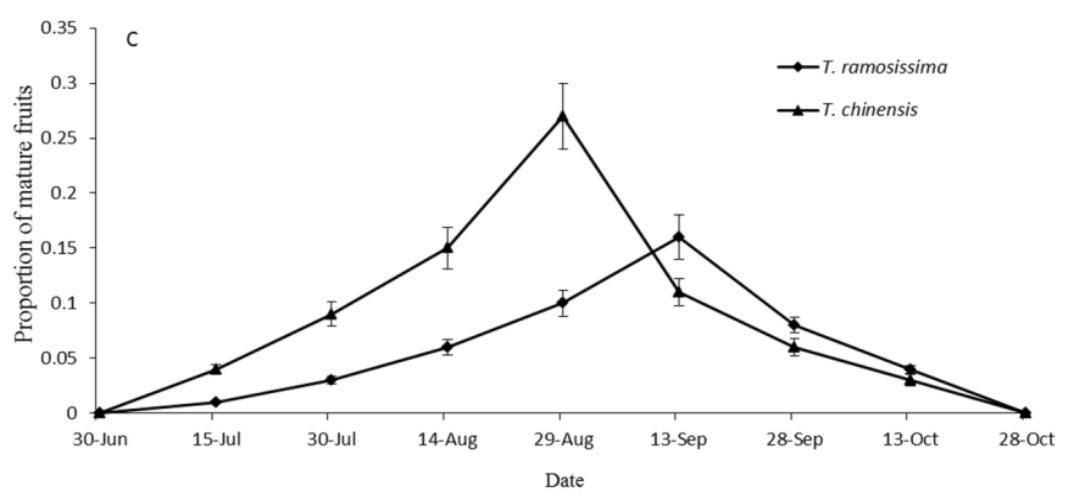

Figure 2. Phenology of T. chinensis and T. ramosissima

Note. Proportion of reproductive structures: Flower buds, flowers in anthesis, mature fruits availability. Average number $\pm \mathrm{SE}$ of phenological state structures per individual of T. chinensis and T. ramosissima throughout the reproductive season in six plots.

\subsection{Floral Traits}

In T. chinensis, the flowers began opening around 07:00 and were completely open around 09:00. Each flower remained open during the day and began to close around 16:30, and in general was fully closed around 19:00. T. ramosissima flowers usually opened around 08:00 and were closed around 15:00 (Table 1). Number of flowers produced per individual was similar in both species, but the average density of individual plants in $T$. chinensis (217.5 \pm 23.6$)$ was significantly higher than that in T. ramosissima $(156.2 \pm 19.7, \mathrm{df}=1, \mathrm{P}<0.05)$. Consequently, a total availability of flowers per day in $T$. chinensis was significantly higher than that in $T$. ramosissima $(\mathrm{df}=1$, $\mathrm{P}<0.05)$.

Each individual flower typically lasted from three to five days in T. chinensis and three days in T. ramosissima. In $T$. chinensis, the leaf was oblong-lanceolate, $1.5-3 \mathrm{~mm}$ long. The length of corolla, petals and stamens was $2.56 \pm 0.21,2.01 \pm 0.12$ and $3.12 \pm 0.27 \mathrm{~mm}$ (Mean $\pm \mathrm{SD}$ ) respectively. In T. ramosissima, the leaf had a long oval shape, $0.5-2 \mathrm{~mm}$ long. The length of corolla, petals and stamens was $1.96 \pm 0.18,1.52 \pm 0.11$ and $1.96 \pm 0.15 \mathrm{~mm}$.

Nectar was secreted by the stylar appendages during the entire period of flower anthesis and nectar deposited at the base of the tube in both species.

Table 1. Timing of flower anthesis of T. chinensis and T. ramosissima

\begin{tabular}{llc}
\hline \multirow{2}{*}{ Event } & \multicolumn{2}{c}{ Time (h) } \\
\cline { 2 - 3 } & T. chinensis & T. ramosissima \\
\hline Anthesis begins & $07: 00-08: 00$ & $08: 00-08: 30$ \\
Flowers completely open & $09: 00-11: 30$ & $10: 30-12: 00$ \\
Pollen release & $08: 30-16: 30$ & $09: 00-15: 30$ \\
Starting of flower closing & $16: 30-17: 30$ & $15: 00-16: 00$ \\
Flowers completely closed & $18: 00-19: 00$ & $18: 00-18: 30$ \\
\hline
\end{tabular}

\subsection{Pollen Limitation}

Pollen limitation was significantly more intensive in T. ramosissima $(\mathrm{PLc}=0.447 \pm 0.032)$ than that in $T$. chinensis $(\mathrm{PLc}=0.438 \pm 0.034)$. In $T$. chinensis, fruit set did not differ significantly between $\mathrm{C}$ and $\mathrm{CC}$ flowers (56.2 $\pm 3.7 \%$ in C flowers, and $48.1 \pm 3.1 \%$ in CC flowers). The fruit set of PA flowers was $83.5 \pm 5.2 \%$ (Figure 3), showing the negative impact of pollen limitation (Table 2). In T. ramosissima, similar fruit set was also found, $52.3 \pm 3.6 \%$ in $\mathrm{C}$ flowers, and $46.2 \pm 3.2 \%$ in CC flowers. In addition, fruit set of PA flowers was $81.6 \pm 4.9 \%$ (Figure 3).

Experimental pollen supplementation did significantly increase the fruit set $(\mathrm{P}<0.05)$ (Figure 3). The results also indicated that pollen limitation in T. ramosissima was more severe than that in T. chinensis (Table 2). 


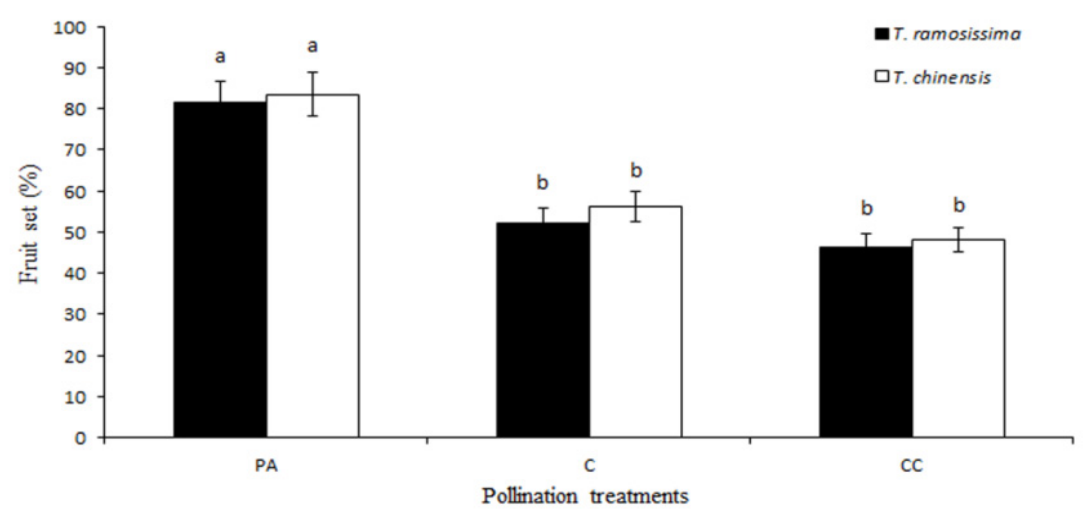

Figure 3. The mean fruit set under different pollination treatments

Note. Black bars indicate the fruit set of T. ramosissima and white bars indicate T. chinensis. Pollination treatments: C, control; CC, procedural control; PA, pollen added (see text for details). Vertical bars denote standard error.

Table 2. Effect of pollination treatments on T. chinensis and T. ramosissima reproductive output

\begin{tabular}{|c|c|c|c|c|c|c|}
\hline & & \multirow{3}{*}{$d f$} & \multicolumn{4}{|c|}{ Fruit set } \\
\hline & & & \multicolumn{4}{|c|}{ T. ramosissima } \\
\hline & & & $\mathrm{F}$ & $\mathrm{P}$ & $\mathrm{F}$ & $\mathrm{P}$ \\
\hline \multirow[t]{3}{*}{ PA vs. C } & Treatment(T) & 1 & 355.102 & $<0.01$ & 381.254 & $<0.01$ \\
\hline & $\operatorname{Patch}(\mathrm{P})$ & 5 & 3.073 & 0.028 & 3.611 & 0.014 \\
\hline & $\mathrm{T} \times \mathrm{P}$ & 5 & 3.629 & 0.014 & 2.547 & 0.055 \\
\hline \multirow[t]{3}{*}{ PA vs. CC } & Treatment(T) & 1 & 524.203 & $<0.01$ & 479.468 & $<0.01$ \\
\hline & $\operatorname{Patch}(\mathrm{P})$ & 5 & 1.851 & 0.141 & 3.258 & 0.022 \\
\hline & $\mathrm{T} \times \mathrm{P}$ & 5 & 1.698 & 0.174 & 4.392 & 0.006 \\
\hline \multirow[t]{5}{*}{ C vs. CC } & Treatment(T) & 1 & 3.515 & 0.073 & 3.679 & 0.067 \\
\hline & $\operatorname{Patch}(\mathrm{P})$ & 5 & 0.461 & 0.802 & 0.359 & 0.871 \\
\hline & $\mathrm{T} \times \mathrm{P}$ & 5 & 3.082 & 0.027 & 1.528 & 0.219 \\
\hline & PLc index & & \multicolumn{2}{|c|}{$0.438 \pm 0.034$} & \multicolumn{2}{|c|}{$0.447 \pm 0.032$} \\
\hline & PLcc index & & \multicolumn{2}{|c|}{$0.497 \pm 0.039$} & \multicolumn{2}{|c|}{$0.503 \pm 0.043$} \\
\hline
\end{tabular}

Note. PA, pollen added treatment; $\mathrm{C}$, control treatment; $\mathrm{CC}$, procedural control treatment.

\subsection{Floral Visitors}

The most frequent visitors to T. chinensis and T. ramosissima were bees (Hymenoptera), Episyrphus balteatus, Metasyrphus corollae, and Pieris rapae were also recorded (Figure 4). These pollinators visited the flowers from the time they opened until they closed, taking with nectar and pollen from other flowers. Six species of insects considered effective or occasional pollinators, were selected for the pollen study. According to pollen analysis, most of bees were efficient pollinators since with their large and hairy bodies they could carry and deposit significantly more pollen on stigmas per visit than other insects. Bees also visited more flowers per minute than the small cabbage butterfly, Pieris rapae.

In T. chinensis, Megachile (Amegachile) kagiana was the most frequent and effective pollinator, because their bodies carried the highest amount of pollen grains per visit. The bees visited almost all nearby flowers in anthesis, and even returned to feed on the same flowers visited previously. The visits peaked from 08:00 to 16:00 (Figure 5).

In T. ramosissima, Episyrphus balteatus and Apis mellifera were also observed. Because of its minimal contact 
with stigmas and reduced pollen load, these species played only a minor role in pollination. Ichneumon sp. and Eristalinus aeneus were also observed but at lower frequencies. The visits peaked from 09:00 to 15:00. These pollinators showed a tendency of the high foraging in the morning and decreased thereafter, and no bee was observed after 19:00.

In the studied sites, the highest and the lowest $\mathrm{V}_{\mathrm{f}}$ was $5.37 \pm 0.5,3.12 \pm 0.3$ respectively. In addition, the outcomes also revealed that a negative relationship between pollinator visitation frequency and $\mathrm{PL}_{\mathrm{C}}$ index in both species (Figure 6, Table 3).

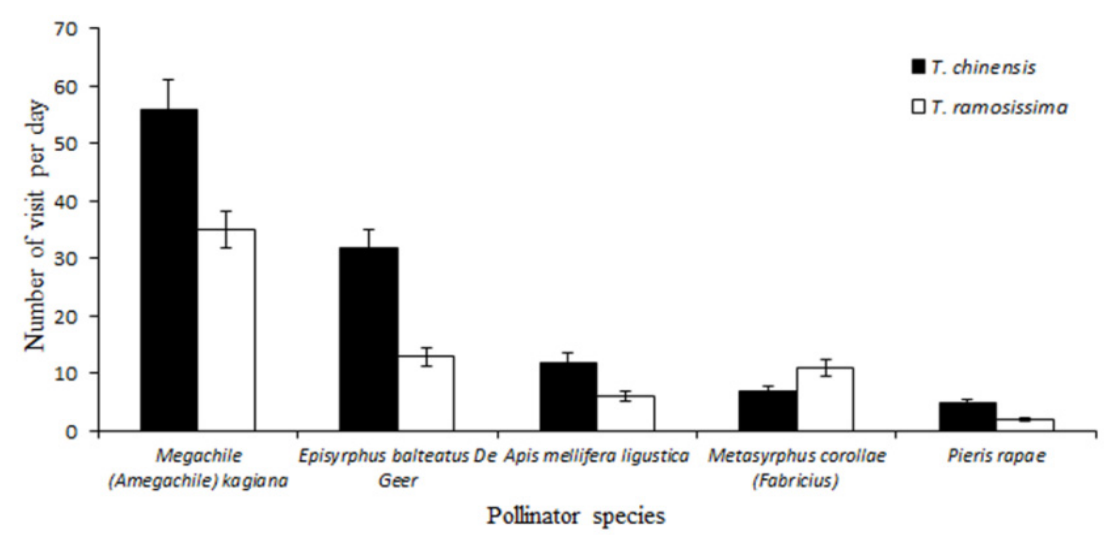

Figure 4. Number of visits of animal species to flowers of T. chinensis and T. ramosissima

Note. Black bars indicate visits number of T. chinensis and white bars indicate number of T. ramosissima.

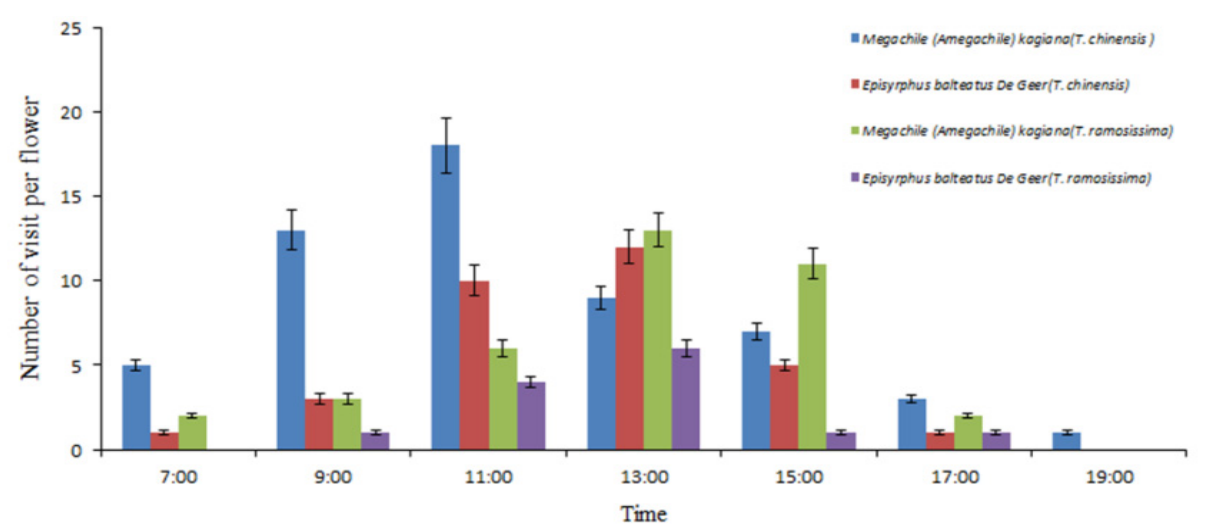

Figure 5. Frequency of insect visits over time to flowers of T. chinensis and of T. ramosissima

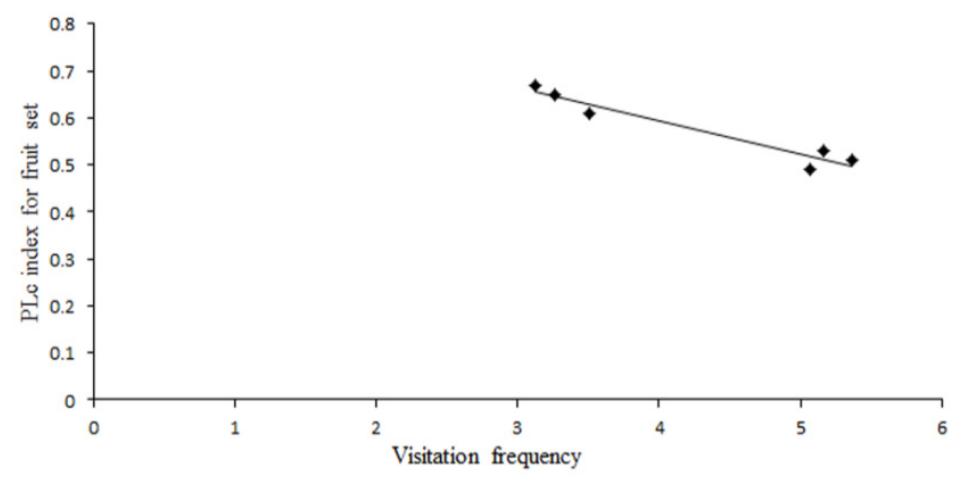

Figure 6. Relationships between $\mathrm{PL}_{\mathrm{C}}$ index per plot and visitation frequency

Note. $\mathrm{PL}_{\mathrm{C}}$ is the pollen limitation under $\mathrm{C}$ treatment. 
Table 3. Plot size, visitation frequency of $T$. chinensis and T. ramosissima $\left(\mathrm{V}_{\mathrm{f}}\right)$ and estimates of pollen limitation for fruit set

\begin{tabular}{llll}
\hline Plot & Plot size & $\mathrm{V}_{\mathrm{f}}$ & Fruit set \\
\hline 1 & 20 & $3.12 \pm 0.3^{\mathrm{a}}$ & $0.67 \pm 0.07^{\mathrm{a}}$ \\
2 & 18 & $3.26 \pm 0.3^{\mathrm{a}}$ & $0.65 \pm 0.07^{\mathrm{a}}$ \\
3 & 17 & $3.51 \pm 0.4^{\mathrm{a}}$ & $0.61 \pm 0.06^{\mathrm{a}}$ \\
4 & 22 & $5.07 \pm 0.5^{\mathrm{b}}$ & $0.49 \pm 0.05^{\mathrm{b}}$ \\
5 & 15 & $5.16 \pm 0.5^{\mathrm{b}}$ & $0.53 \pm 0.05^{\mathrm{b}}$ \\
6 & 21 & $5.37 \pm 0.5^{\mathrm{b}}$ & $0.51 \pm 0.05^{\mathrm{b}}$ \\
\hline
\end{tabular}

Note. Plot size refers to the number of flowering plants in the patch. $\mathrm{V}_{\mathrm{f}}$ is visits/(flower-h). Plot 1, 2 and 3 were study areas of $T$. ramosissima; Plot 4,5 and 6 were study areas of $T$. chinensis. Different superscript letters indicate significant differences at $\alpha<0.05$.

\subsection{Breeding System}

Seed set obtained in each pollination treatment group is shown in Table 4. Compared to non-manipulated self-pollination experiment, we found that the seed set of $T$. chinensis and $T$. ramosissima was significantly higher in the manual cross-pollination treatment (Chi-square test, $\mathrm{P}<0.01$ ). This indicated that outcrossing was the most efficient pollination method in both species. In $T$. chinensis, the manual cross-pollination treatment resulted in $71.2 \pm 7.6 \%$ seed set, and $63.2 \pm 7.1 \%$ in $T$. ramosissima. Seed set of $T$. chinensis was significantly higher than that of $T$. ramosissima (Chi-square test, $\mathrm{P}<0.05$ ). The seed set of the manual self-pollination samples was $14.1 \%$ in $T$. ramosissima. The SCI (self-compatibility index) was 0.22 for A. venetum, which indicated that this species was self-compatible.

Under natural conditions but in the absence of biotic pollinators, as modeled in the netting experiments, the flowers of both species produced only a small amount of seed. Emasculated under natural conditions, the flowers were able to produce a lot of fruits, significantly more than the seed set of netting treatment (Chi-square test, $\mathrm{P}<$ 0.05). This indicated that insect pollination was required for both species.

In non-manipulated self-pollination experiment, the seed set of $T$. ramosissima was significantly higher than that of $T$. chinensis (Chi-square test, $\mathrm{P}<0.05$ ). We found that $T$. ramosissima had a more effective self-pollination mechanism.

Table 4. Seed set of $T$. chinensis and T. ramosissima in different treatments

\begin{tabular}{lll}
\hline \multirow{2}{*}{ Treatments } & \multicolumn{2}{c}{ Seed set (\%) } \\
\cline { 2 - 3 } Control & T. chinensis & T. ramosissima \\
Manual cross-pollination & $52.3 \pm 6.1$ & $45.3 \pm 5.2$ \\
Non-manipulated self-pollination & $71.2 \pm 7.6$ & $63.2 \pm 7.1$ \\
Manual self-pollination & $4.1 \pm 0.5$ & $6.2 \pm 0.7$ \\
Emasculated and netting & $17.5 \pm 1.5$ & $14.1 \pm 1.6$ \\
Emasculated without bags & $13.6 \pm 1.8$ & $10.9 \pm 1.2$ \\
\hline
\end{tabular}

\section{Discussion}

\subsection{Phenology, Floral Traits and Pollinators}

Phenological studies indicated that the time of anthesis was different between T. chinensis and T. ramosissima. T. chinensis lasted five days under natural conditions while flowers of $T$. ramosissima only lasted three days. Longer blooming duration and flowering peak suggested that height of the studied plants influenced the period 
of flower production.

Most plants of the studied species are scattered and usually grow within shrub vegetation, thus growing higher than associated plants is important. Between the both species studied, most of $T$. chinensis grew higher than $T$. ramosissima. Growing taller is likely to be an adaptation of $T$. chinensis for improving incidence of solar radiation on the plants and attract pollinators. Similar patterns of phenological variation were previously documented between Pedicularis rex subsp. lipkyana and P. rex subsp. rex (Orobanchaceae), height of the studied plants and incidence of solar radiation on the plants were identified as major causes (Tang et al., 2007). The solar radiation effectively influenced the period of flower production. Pollinators also preferably visited $T$. chinensis than T. ramosissima because the former had the larger corolla and higher density of flower resources. This was likely the main cause explaining the different reproductive success between the both species.

In flower patches of the species, pollinator visitation rates and pollen flow are expected to increase with floral density, but pollinator visits may lead to interspecific pollen deposition, interference and pollen discount (Rathcke, 1983). T. chinensis and T. ramosissima shared most pollinators, and interference may contribute to pollen limitation. Observed differences in visitation time and intensity may help to reduce interspecific pollen flow and interference.

T. chinensis and T. ramosissima shared the same pollinators as expected, as these species showed the similar phenological traits. Ji et al. (2009) observed the flowers of Tamarix ramosissima are pollinated by several small insects, including bees and flies. M. (A.) kagiana was observed to have the highest visitation frequency, but Episyrphus balteatus was the species with most suitable size for performing pollination. Flower opening and pollen release occurred between 09:00 and 16:00 h, which represents the most crucial time for pollination. This period coincided with the activity of $M$. (A.) kagiana, and also partially with the activity of A. mellifera. In addition, the flowering duration was earlier in T. chinensis than that in T. ramosissima. It can be inferred that the mutual adaptation between floral traits and pollinators is the effective reproductive biology, in accordance with the evolution of the both species breeding system. The genus Megachile includes a great number of species, and their females have a characteristic scopa in the ventral surface of the abdomen for collecting and transporting pollen (Silveira et al., 2002). The density of flowers in $T$. chinensis was also markedly higher than in the $T$. ramosissima. This pattern indicated that $M$. (A.) kagiana preferred to visit areas with greater resource availability.

\subsection{Pollen Limitation and Resource Reallocation}

Pollen limitation, a decrease in potential plant reproduction due to inadequate supply of pollen, is ubiquitous especially for Angiosperms (Ashman et al., 2004; Knight et al., 2005). Understanding causes of pollen limitation and resource reallocation will improve prediction of its consequences for plants in arid habitats. Many studies have found self-incompatible plants are more prone to being pollen-limited than self-compatible plants because self-compatible ones can mitigate the effects of pollinator scarcity by autogamy (Burd, 1994; Larson \& Barrett, 2000; Knight et al., 2005). However, our study indicated that $T$. chinensis and T. ramosissima were pollen-limited since significant differences were found between the PA treatment and the Control across plots. Similar patterns of pollen limitation were previously documented between Erysimum mediohispanicum and Erysimum popovii, and these were self-compatible (Gómez et al., 2010; Fernández et al., 2012). These studies demonstrated that pollen limitation can also affect self-compatible plants.

Resource reallocation from untreated to pollen-supplemented flowers is always a major concern in Pollen Limitation. The experiments of pollen limitation may give misleading results because plants can reallocate resources among flowers in response to hand-pollinated. We could not submit whole individual plants to control or experimental treatments (Ashman et al., 2004), because T. chinensis and T. ramosissima individual can produce several hundred flowers. To avoid confounding results, we used two complementary controls, one from manipulated plants and the other from non-manipulated, to detect potential reallocation (Wesselingh, 2007; Gómez et al., 2010). If resource reallocation existing, controls in non-manipulated plants would be expected to have higher rather than lower reproduction than controls in manipulated plants. The outcomes indicated that pollen added to some flowers did not divert resources from accompanying flowers, suggesting that resource reallocation did not significantly alter our results.

Recently investigators have proposed that limitation in pollinator visits is the main reason for pollen limitation (Aizen \& Harder, 2007; Gómez et al., 2010). Limitation in pollinator visits can occur because pollinators are rare or they prefer visiting other attractive plants (Wilcock \& Neiland, 2002; Mitchell et al., 2009). In addition, some studies also found that pollen limitation was related to the quantity of pollinators and even pollinator abundance was a primary factor driving pollen limitation (Knight et al., 2006; Cosacov et al., 2008). Our outcomes support 
this idea, suggesting that a negative relationship between pollinator visitation frequency and $\mathrm{PL}_{\mathrm{C}}$ index of both species.

\subsection{Pollinator Behavior and Reproductive success of T. chinensis and T. ramosissima}

During the insect pollination process, pollinator behavior has pervasive effects on reproduction success. In addition, there are many extrinsic factors that can affect pollinator behavior, such as wind velocity and floral color (Waddington, 1983). More specifically, pollen and nectar are the major rewards that are presented to pollinators (Jay, 1986).

While the primary pollinator behavior is similar in the both species, specific differences are apparent. Corolla morphology is closely related to pollination behavior and might be the result of coadaptation to pollinators' morphology. In T. chinensis, $M$. (A.) kagiana entered the corolla tube to extract nectar, due to the corolla was high and nectar deposited at the base of the tube. M. (A.) kagiana landed on the stamens of the flowers, and extracted nectar from the flower tube using their proboscises. When the pollinator's head and thorax entered the corolla tube, the stigma became directed to the region separating the pollinator's head and thorax. While extracting nectar, pollen from the anthers accumulated on their legs and abdomen. Some of that pollen remained on the upper portion of the stigma after the bees moved from one flower to the next.

The smaller corolla in T. ramosissima may restrict access of pollinators to the corolla tube from the front of the flowers. The corolla mouth was smaller than even the smallest sized pollinators. To imbibe the nectar at the base of corolla tube, pollinators needed to force themselves into the corolla tube. In T. ramosissima, A. mellifera entered the corolla tube from the right side of the flower. Then the stigma contacted the left side of the abdomen.

The controlled pollination treatments revealed that outcrossing was a more effective system for two species in terms of fruit set. In addition, the morphology of the flowers forced the pollinators to touch the stigmas before touching the anthers, thus favoring outcrossing. This study of plant reproduction also indicated that $T$. chinensis and $T$. ramosissima were self-compatible. However, self-pollination played an important supporting role in the breeding system when conditions for outcrossing were unfavorable. When there is a scarcity of suitable pollinators under stressful environmental conditions, plants may carry out self-pollination instead of cross-pollination in order to ensure reproduction success. If self-pollen has a greater chance to pollinate the ovary than the cross-pollen, self-pollination may promote pollination success, which is an advantage selection (Jay, 1986). Thus, both species displays a highly adaptive breeding system. In addition, this outcome found low densities of pollinators work against the effective pollination and seed set, but plants with self-pollination mechanism may be favored in these harsh conditions. This finding indicated T. ramosissima had a more effective self-pollination mechanism than $T$. chinensis. T. ramosissima may use complex variations of these strategies to ensure reproductive success.

\section{Acknowledgements}

This research was funded by Integrative research in key techniques for sustainable restoration of Sandy Land Ecosystems (2011BAC07B02), Research in techniques for risk assessment and prediction of Sandy Land Ecosystem (Y439K71001), "One Hundred Talent" Program of Chinese Academy of Sciences (Y451H31001) and National Natural Science Foundation of China (41401620). We thank Naiman Desertification Research Station and Urat Desert-grassland Research Station for all the help and support during this study. MC and XYZ conceived and designed the experiments. MC and XYZ wrote the manuscript; other authors provided editorial advice.

\section{References}

Ai, H. L., Zhou, W., Xu, K., Wang, H., \& Li, D. Z. (2013). The reproductive strategy of a pollinator-limited Himalayan plant, Incarvillea mairei (Bignoniaceae). BMC Plant Biology, 13, 195. http://dx.doi.org/10.1186/1471-2229-13-195

Aizen, M. A., \& Harder, L. D. (2007). Expanding the limits of the pollen-limitation concept, effects of pollen quantity and quality. Ecology, 88, 271-281. http://dx.doi.org/10.1890/06-1017

Arias-Cóyotl, E., Stoner, K. E., \& Casas, A. (2006). Effectiveness of bats as pollinators of Stenocereus stellatus (Cactaceae) in wild, managed in situ, and cultivated population in La Mixteca Baja, Central Mexico. American Journal of Botany, 93, 1675-1683. http://dx.doi.org/10.3732/ajb.93.11.1675

Ashman, T. L., \& Morgan, M. T. (2004). Explaining phenotypic selection on plant attractive characters, male function, gender balance or ecological context? Proceedings of The Royal Society B-Biological Sciences, 271, 553-559. http://dx.doi.org/10.1098/rspb.2003.2642 
Ashman, T. L., Knight, T. M., Steets, J. A., Amarasekare, P., Burd, M., Campbell, D. R., ... Wilson, W. G. (2004). Pollen limitation of plant reproduction, ecological and evolutionary causes and consequences. Ecology, 85, 2408-2421. http://dx.doi.org/abs/10.1890/03-8024

Baum, B. R. (1978). The genus Tamarix. Israel Academy of Sciences and Humanities, Jerusalem.

Beattie, A. J. (1971). Technique for Study of Insect-Borne Pollen. Pan-Pacific Entomologist, 47, 82.

Bond, W. J. (1994). Do mutualisms matter, assessing the impact of pollinator and disperser disruption on plant extinction. Philosophical Transactions of the Royal Society of London, Series B, Biological Sciences, 344, 83-90. http://dx.doi.org/10.1098/rstb.1994.0055

Burd, M. (1994). Bateman's principle and plant reproduction, the role of pollen limitation in fruit and seed set. Botanical Review, 60, 83-139. http://dx.doi.org/10.1007/BF02856594

Byers, D. L. (1995). Pollen quantity and quality as explanations for low seed set in small populations exemplified by Eupatorium (Asteraceae). American Journal of Botany, 82, 1000-1006. http://dx.doi.org/10.2307/2446229

Casper, B. B., \& Niesenbaum, R. A. (1993). Pollen versus resource limitation of seed production, a reconsideration. Current Science, 65, 210-214.

Cosacov, A., Nattero, J., \& Cocucci, A. A. (2008). Variation of pollinator assemblages and pollen limitation in a locally specialized system: The oil-producing Nierembergia linariifolia (Solanaceae). Annals of Botany, 102, 723-734. http://dx.doi.org/10.1093/aob/mcn154

Dafni, A. (1992). Pollination Ecology: A Practical Approach. New York, NY: Oxford University Press.

Fernández, J. D., Bosch, J., Ariza, N., \& Gómez, J. M. (2012). Pollen limitation in a narrow endemic plant, geographical variation and driving factors. Oecologia, 170, 421-431. http://dx.doi.org/10.1007/s00442-012-2312-1

García-Camacho, R., \& Totland, O. (2009). Pollen limitation in the alpine, a meta-analysis. Arctic Antarctic and Alpine Research, 41,103-111. http://dx.doi.org/10.2307/40305861

Glenn, E. P., \& Nagler, P. L. (2005). Comparative ecophysiology of Tamarix ramosissima and native trees in western US riparian zones. Journal of Arid Environments, 61, 419-446. http://dx.doi.org/10.1016/j.jaridenv.2004.09.025

Gómez, J. M., Abdelaziz, M., Lorite, J., Munõz-Pajares, A. J., \& Perfectti, F. (2010). Changes in pollinator fauna cause spatial variation in pollen limitation. Journal of Ecology, 98, 1243-1252. http://dx.doi.org/10.1111/j.1365-2745.2010.01691.x

Hudgeons, J. L., Knutson, A. E., Heinz, K. M., Deloach, C. J., Dudley, T. L., Pattison, R. R., \& Kiniry, J. R. (2007). Defoliation by introduced Diorhabda elongata leaf beetles (Coleoptera, Chrysomelidae) reduces carbohydrate reserves and regrowth of Tamarix (Tamaricaceae). Biological Control, 43, $213-221$. http://dx.doi.org/10.1016/j.biocontrol.2007.07.012

Janzen, D. H. (1977). A note on optimal mate selection in plants. American Naturalist, 111, $365-371$. http://dx.doi.org/10.1086/283166

Jay, S. C. (1986). Spatial management of honey bees on crops. Annual Review of Ecology and Systematics, 31, 49-65. http://dx.doi.org/10.1146/annurev.en.31.010186.000405

Ji, H. J., Yin, L. K., Yan, C., \& Kang, X. S. (2009). Study on floral dynamics, pollen viability and stigma receptivity of Tamarix ramosissima. Journal of Northwest A\&F University, 37, 114-118.

Kearns, C. A., Inouye, D. W., \& Waser, N. M. (1998). Endangered mutualisms: The conservation of plant-pollinator interactions. Annual Review of Ecology and Systematics, 29, 83-112. http://dx.doi.org/10.1146/annurev.ecolsys.29.1.83

Kevan, P. G., Clark, E. A., \& Thomas, V. G. (1990). Insect pollination and sustainable agriculture. American Journal of Alternative Agriculture, 5, 12-22. http://dx.doi.org/10.1017/S0889189300003179

Knight, T. M., Steet, J. A., \& Ashman, T. L. (2006). A quantitative synthesis of pollen supplementation experiments highlights the contribution of resource reallocation to estimates of pollen limitation. American Journal of Botany, 93, 271-277. http://dx.doi.org/10.3732/ajb.93.2.271

Knight, T. M., Steets, J. A., Vamosi, J. C., Mazer, S. J., Burd, M., Campbell, D. R., ... Ashman, T. L. (2005). Pollen limitation of plant reproduction, ecological and evolutionary causes and consequences. Annual 
Review of Ecology and Systematics, 36, 467-497. http://dx.doi.org/10.1890/03-8024

Kudo, G. (1993). Relationships between flowering time and fruit set of the entomophilous alpine shrub, Rhododendron aureum (Ericaceae), inhabiting snow patches. American Journal of Botany, 80, 1300-1304. http://dx.doi.org/10.2307/1552470

Larson, B. M. H., \& Barrett, S. C. H. (2000). A comparative analysis of pollen limitation in flowering plants. Biological Journal of the Linnean Society, 69, 503-520. http://dx.doi.org/10.1006/bij1.1999.0372

Li, X. W., \& Teng, H. K. (1990). The Flora of China. Science Press, Beijing.

Milbrath, L. R., \& Deloach, C. J. (2006). Host specificity of different populations of the leaf beetle Diorhabda elongate (Coleoptera, Chrysomelidae), a biological control agent of saltcedar (Tamarix spp.). Biological Control, 36, 32-48. http://dx.doi.org/10.1016/S1049-9644(03)00003-3

Mitchell, R. J., Flanagan, R. J., Brown, B. J., Waser, N. M., \& Karron, J. D. (2009). New frontiers in competition for pollinators. Annals of Botany, 103, 1403-1413. http://dx.doi.org/10.1093/ aob/mcp062

Morman, P. J., Deloach, C. J., Dudley, T. L., \& Sanabria, J. (2009). Open field host selection and behavior by tamarisk beetles (Diorhabda spp.) (Coleoptera, Chrysomelidae) in biological control of exotic saltcedars (Tamarix spp.) and risks to non-target athel (T. aphylla) and native Frankenia spp. Biological Control, 50, 243-261. http://dx.doi.org/10.1016/j.biocontrol.2009.04.011

Rathcke, B. (1983). Competition and facilitation among plants for pollinators. Academic Press, New York.

Silveira, F. A., Melo, G. A. R., \& Almeida, E. A. B. (2002). Abelhas brasileiras, sistemática e identificação. Belo Horizonte, $\mathrm{MG}$.

Spira, T. P., Snow, A. A., Whigham, D. F., \& Leak, J. (1992). Flower visitation, pollen deposition, and pollen-tube competition in Hibiscus moscheutos (Malvaceae). American Journal of Botany, 79, 428-433. http://dx.doi.org/10.2307/2445155

Stuart, W., \& Stephanie, P. (2010). Reproduction of Echinacea angustifolia in fragmented prairie is pollen-limited but not pollinator-limited. Ecology, 91, 733-742. http://dx.doi.org/10.1890/08-1375.1

Tang, Y., Xie, J. S., \& Sun, H. (2007). The pollination ecology of Pedicularis rex subsp. lipkyana and P. rex subsp. rex (Orobanchaceae) from Sichuan, southwestern China. Flora, 202, 209-217. http://dx.doi.org/10.1016/j.flora.2006.09.001

Waddington, K. E. (1983). Foraging behavior of pollinators. In L. Real (Ed.), Pollination biology. Orlando, FL, USA: Academic Press. http://dx.doi.org/10.1016/b978-0-12-583980-8.50016-8

Wesselingh, R. A. (2007). Pollen limitation meets resource allocation, towards a comprehensive methodology. New Phytologist, 174, 26-37. http://dx.doi.org/10.1111/j.1469-8137.2007.01997.x

Whiteman, K. (2006). Distribution of salt cedar (Tamarix spp. L) along an unregulated river in South-western New Mexico, USA. Journal of Arid Environments, 64, 364-368. http://dx.doi.org/10.1016/j.jaridenv.2005.06.004

Wilcock, C., \& Neiland, R. (2002). Pollination failure in plants, why it happens and when it matters. Trends in Plant Science, 7, 270-277. http://dx.doi.org/10.1016/S1360-1385(02)02258-6

Zapata, T. R., \& Arroyo, M. T. K. (1978). Plant reproductive ecology of a secondary deciduous tropical forest in Venezuela. Biotropica, 10, 221-230. http://dx.doi.org/10.2307/2387907

\section{Copyrights}

Copyright for this article is retained by the author(s), with first publication rights granted to the journal.

This is an open-access article distributed under the terms and conditions of the Creative Commons Attribution license (http://creativecommons.org/licenses/by/3.0/). 